\title{
Reoignimbritos e ignimbritos de alto grau do vulcanismo Acampamento Velho, RS: origem e temperatura de formação
}

\author{
Carlos Augusto Sommer ${ }^{1}$, Evandro Fernandes de Lima ${ }^{1}$, Ronaldo Pierosan ${ }^{1}$ \& \\ Adriane Machado ${ }^{2}$
}

\begin{abstract}
Resumo A Formação Acampamento Velho é constituída por depósitos vulcânicos neoproterozoicos dominantemente ácidos, emplaçados em condições subaéreas sobre o Escudo Sul-Rio-Grandense. Registros deste vulcanismo são encontrados nos platôs da Ramada e Taquarembó localizados no sudoeste do Estado do Rio Grande do Sul. Este magmatismo varia de metaluminoso a peralcalino e apresenta afinidade alcalina sódica. Nos depósitos de fluxo piroclásticos dominam fragmentos juvenis, como púmices, shards e fragmentos vítreos maciços. Estes apresentam um típico elevado grau de soldagem com ignimbritos, com alto grau nas porções de base e intermediárias, e reoignimbritos no topo. Os cálculos de temperaturas pré-eruptivas obtidas na saturação em zircão mostram valores entre $870-978^{\circ} \mathrm{C}$ para o Platô do Taquarembó e de $850-946^{\circ} \mathrm{C}$ para o Platô da Ramada. Os valores de viscosidade calculados variam de 4,77 x $10^{7}$ a 1,39 x $10^{8} \mathrm{~Pa}$ s para os reoignimbritos, e $1,72 \times 10^{11}$ a $6,55 \times 10^{11} \mathrm{~Pa}$ s para os ignimbritos. Os conteúdos de $\mathrm{Zr}$ crescem em direção ao topo da sequência piroclástica indicando aumento da peralcalinidade, que determinou a redução da viscosidade dos clastos nas porções superiores dos fluxos. Um modelo agradacional progressivo permite explicar as variações verticais no tamanho e tipos de clastos, e na geoquímica do depósito. Este modelo assume a aglutinação de partículas juvenis quentes durante o deslocamento do fluxo, o que espessa progressivamente o depósito. Portanto, a elevada soldagem e o reomorfismo são sin-deposicionais. Os fluxos piroclásticos de alta temperatura dos platôs da Ramada e Taquarembó foram gerados a partir de baixas colunas de erupção e podem ser interpretados como depósitos ignimbríticos extracaldeira.
\end{abstract}

Palavras-chave: vulcanismo, depósitos ignimbríticos, soldagem, rochas ácidas.

\begin{abstract}
Reoignimbrites and high-grade ignimbrites of Acampamento Velho volcanism, RS: origin and formation temperature. The Acampamento Velho Formation is constituted by neoproterozoic volcanic deposits of dominantly acid composition, which were emplaced under subaerial conditions on Sul-RioGrandense Shield. The volcanism registration have been found at Ramada and Taquarembó plateaus localized at southwest of Rio Grande do Sul State. This magmatism varies from metaluminous to peralkaline and shows alkaline sodic affinity. At the pyroclastic flow deposits dominate juvenile fragments such as pumices, shards and massive vitreous fragments, which show a typical high welding degree with ignimbrites, being high degree at the base and intermediate portions, and reoignimbrites at the top. The pre-eruptive temperature calculations obtained at the saturation of zircon show values between $870-978^{\circ} \mathrm{C}$ for Taquarembó Plateau and $850-946^{\circ} \mathrm{C}$ for Ramada Plateau. The calculated viscosity values vary from $4.77 \times 10^{7}$ to $1.39 \times 10^{8} \mathrm{~Pa}$ s for the reoignimbrites, and $1.72 \times 10^{11}$ to $6.55 \times 10^{11} \mathrm{~Pa} \mathrm{~s}$ for the ignimbrites. $\mathrm{Zr}$ contents increase to the pyroclastic sequence top, indicating increasing of peralkalinity, which determined the viscosity reduction of clasts at the upper portions of the flows. The progressive aggradacional model allows explaining the vertical variations at the clast size and type, and at the geochemistry of the deposit. This model assumes the agglutination of hot juvenile particles during the flow movement, which becomes the deposit progressively thicker. Therefore, the high welding degree and the reomorfism are sin-depositional. The high temperature pyroclastic flows of Ramada and Taquarembó plateaus were generated from low eruption columns and can be interpreted as extracaldera ignimbritic deposits.
\end{abstract}

Keywords: volcanism, ignimbrite deposits, welding, silicic rocks.

INTRODUÇÃO Os processos sin- e pós-deposicionais sobre depósitos vulcânicos são responsáveis por modificações de estruturas e texturas originais, independente do tipo de mecanismo de erupção e de transporte. Entre estes, a soldagem é considerada um mecanismo de deformação eficiente que envolve a cimentação conjunta de fragmentos vesiculares e vítreos, além da adesão de fragmentos parcialmente fundidos em fluxos viscosos de alta temperatura (e.g. Smith 1960b, Guest \& Rogers 1967, Riehle et al. 1995). A soldagem causa variações nas estruturas, texturas e propriedades físicas das rochas (e.g. adensamento, diminuição da porosidade), observadas principalmente em depósitos de fluxo piroclásticos (e.g. Smith 1960a, 
1960b, 1979, Ross \& Smith 1961, Ragan \& Sheridan 1972, Peterson 1979, Streck \& Grunder 1995, Quane et al. 2004), sendo a intensidade quantificada pelo grau de soldagem (Wright et al. 1980, Walker 1983).

Diversos trabalhos envolvendo aspectos teóricos e experimentais consideram que a soldagem pode ser influenciada pela interação dinâmica entre os mecanismos de erupção, deposição e resfriamento do depósito vulcânico.

Depósitos vulcânicos soldados incluem aglutinados, fluxos piroclásticos, depósitos de queda e de respingo, base e margens de fluxos em depósitos efusivos, além de condutos vulcânicos (Smith 1960a, 1960b, Boyd 1961, Sparks \& Wright 1979, Naranjo et al. 1992, Sparks et al. 1993, Kano et al. 1997, Wolff \& Sumner 2000, Gottsman \& Dingwell 2001, Tuffen et al. 2003). Abrangem um amplo espectro composicional, desde basaltos até riolitos, porém os estudos concentram-se especialmente em ignimbritos ácidos. O processo de soldagem tende a ser especialmente eficiente em sistemas peralcalinos, que exibem com frequência feições relacionadas ao reomorfismo (e.g. Schmincke \& Swanson 1967, Wolff \& Wright 1981, Kobberger \& Schmincke 1999).

O grau de soldagem está relacionado essencialmente à viscosidade, temperatura do fluxo e espessura do depósito e estabelece-se durante e após a deposição, resultando em diferentes estruturas e texturas (Branney \& Kokelaar 1992).

Nos depósitos piroclásticos de fluxo de grau baixo, praticamente todas as porções não estão soldadas, ao passo que em depósitos de grau moderado, a soldagem dos depósitos não é necessariamente homogênea, observando-se zonas soldadas, moderadamente soldadas a não soldadas. Esta zonalidade é facilmente observada em unidades de fluxo simples, sendo mais complexa em unidades de fluxo compostos.

Em depósitos piroclásticos de fluxo de grau alto, o processo de soldagem pode ser extremamente elevado, onde partes do depósito são texturalmente indistinguíveis de derrames, sendo nestes casos denominados por ignimbritos do tipo lava-like (Ekren et al. 1984, Henry et al. 1988). Em geral estes ignimbritos apresentam zonas de maior intensidade de soldagem, onde as estruturas passam a ser formadas pela deformação originada de fluxos não particulados, durante e após a deposição, sendo muitas vezes um processo contínuo, denominado reomorfismo (Schmincke \& Swanson 1967, Chapin \& Lowell 1979, Wolff \& Wright 1981, Branney et al. 1992).

Os fluxos de púmices (ignimbritos), quando em superfícies inclinadas, podem fluir reomorficamente, semelhante a líquidos viscosos, sendo a fricção intergranular eliminada devido à elevada soldagem. Um completo espectro de deformações pode ocorrer nestes casos: (i) estiramento e boudinage de fiamme achatados, (ii) deformação do acamamento interno e das estruturas de soldagem, gerando dobramentos com amplitudes milimétricas a decamétricas, (iii) comportamento de todo o fluxo como um "líquido" produzindo feições observadas em derrames de mesma composição. Em condições de altas temperaturas, partículas parcialmente líquidas podem tornar-se achatadas devido a seu próprio peso e aglutinarem-se umas com as outras, fluindo ao longo da superfície do terreno. Nestes casos, a soldagem ocorre como um processo sin-deposicional e é controlada diretamente pela viscosidade e dinâmica de deposição.

No Brasil, os depósitos soldados são encontrados em diversas sequências vulcânicas (Iriri, Riozinho, Iricoumé, Campo Alegre, Bacia do Camaquã etc.) e muitas vezes intercaladas entre depósitos efusivos, de queda e do tipo surge. A identificação da soldagem, em geral, é utilizada como uma evidência para definição do tipo de depósito e da fácies, não sendo explorados os aspectos que determinaram a origem e a intensidade desta.

O presente trabalho coloca em discussão o significado da soldagem em ignimbritos riolíticos da Formação Acampamento Velho nos platôs do Taquarembó e Ramada, integrando descrições detalhadas de campo com a petrografia e litoquímica. Esta sequência vulcânica ácida pertence à Bacia do Camaquã e tem sido objeto de diversas investigações, justificando desta forma, a escolha desta unidade para a discussão (e.g. Ribeiro et al. 1966, Sommer 1994, Wildner et al. 1997, 1999, 2002, Zerfass \& Almeida 1997, Sommer et al. 1999, 2003, 2005, 2006, Almeida et al.1998, 2002).

PROCEDIMENTOS ANALÍTICOS Os estudos litoquímicos fundamentaram-se nas análises químicas de amostras de ignimbritos representativas dos diferentes litotipos. Os elementos maiores e traço foram analisados no Activation Laboratories Ltd., Ontário, Canadá, utilizando a técnica de ICP (Inductively Coupled Plas$m a$ ) para os elementos maiores e ICP-MS (Inductively Coupled Plasma Microspectrometry) para os elementos traço e terras raras.

Os dados de temperatura foram calculados a partir da metodologia de Watson (1979) e Watson \& Harrison (1983), envolvendo a composição química de rocha total (elementos maiores e $\mathrm{Zr}$ ), aplicada a composições com $\mathrm{H}_{2} \mathrm{O}>2 \%$ e valores do parâmetro $\mathrm{M}$ entre 0,9 e $2,1[\mathrm{M}=(\mathrm{Na}+\mathrm{K}+2 \times \mathrm{Ca}) /(\mathrm{Al} \times \mathrm{Si}($ Hanchar \& Watson 2003). Comparativamente, outros dados de temperatura foram obtidos através da metodologia de Sisson \& Grove (1993), envolvendo somente a composição de elementos maiores.

Os dados de viscosidade foram calculados a partir da equação de Einstein-Roscoe (McBirney \& Murase 1984) que considera, além da composição química (elementos maiores), a temperatura, pressão, volume e dimensão dos cristais e/ou vesículas. A partir da petrografia foram utilizados os seguintes parâmetros: ignimbritos reomórficos: $5 \%$ de cristais/fragmentos/ vesículas com dimensão média de $1 \mathrm{~mm}$; ignimbritos não reomórficos: $30 \%$ de cristais/fragmentos/vesículas com dimensão média de $3 \mathrm{~mm}$. A pressão assumida foi de aproximadamente $1 \mathrm{~atm}$ e os dados de temperatura foram extraídos dos cálculos descritos acima.

Para o cálculo de viscosidade e temperatura foi utilizado o programa KWare-Magma (Wohletz 2007). 


\section{CONTEXTO GEOLÓGICO}

Bacia do Camaquã A Bacia do Camaquã está relacionada aos estágios pós-colisionais do ciclo Brasiliano-Pan-Africano e pode ser considerada do tipo strike-slip, embora seja ainda bastante controvertida a sua classificação e mecanismos de geração (Brito Neves \& Cordani 1991, Gresse et al. 1996, Chemale Jr. 2000, Paim et al. 2000). Entende-se neste trabalho como pós-colisional, um período complexo, posterior ao da colisão principal que inclui grandes movimentos ao longo de zonas de cisalhamento transcorrentes, colisão oblíqua, delaminação litosférica, rifteamento, subducção de pequenas placas oceânicas e vulcanismo associado à sedimentação em bacias do tipo strike slip (e.g. Liégeois 1998, Bonin 2004).

Em termos de evolução geológica, esta bacia pode ser interpretada como um locus deposicional caracterizado pela alternância de intervalos, onde dominaram eventos deposicionais com o acúmulo de espessos pacotes sedimentares e vulcano-sedimentares, e intervalos dominantemente erosionais (Paim et al. 2000). Nas fases de preenchimento, os episódios vulcânicos dominaram, normalmente, na base das unidades de maior hierarquia, seguidos pela deposição de sedimentos predominantemente siliciclásticos. Este contexto dinâmico, envolvendo eventos ígneos, sedimentares e deformacionais gerou um complexo padrão de preenchimento, representado por uma série de unidades estratigráficas (Paim et al. 2000).

O magmatismo neoproterozoico-ordoviciano da Bacia do Camaquã evoluiu de termos toléticos e cálcico-alcalinos alto-K, a shoshoníticos, até alcalino sódicos, sendo a contribuição crustal representada por granitoides peraluminosos (Wildner et al. 2002, Sommer et al. 2006, Lima et al. 2007) (Fig. 1).

As rochas vulcânicas mais antigas têm composições dominantemente intermediárias, além de básicas e ácidas, de afinidade shoshonítica (Formação HilárioRibeiro \& Fantinel 1978 ou Aloformação Hilário-Paim et al. 2000). Dados de U-Pb e Ar-Ar obtidas nas rochas vulcânicas da Formação Hilário indicam idades de 585 a $590 \mathrm{Ma}$ (Janikian et al. 2008).

O vulcanismo de afinidade alcalina sódica denominado de Formação Acampamento Velho (Ribeiro \& Fantinel 1978 ou Aloformação Acampamento VelhoPaim et al. 2000) sucede o magmatismo shoshonítico e é constituído por depósitos explosivos/efusivos dominantemente ácidos. Análises U-Pb SHRIMP em zircões extraídos de riolitos resultaram em idades de cerca de $574 \mathrm{Ma}$ (Chemale Jr. 2000, Janikian et al. 2008), na região do Passo do Salsinho e 550 Ma na região do Platô da Ramada (Sommer et al. 2005).

As últimas manifestações vulcânicas da Bacia do Camaquã (Membro Rodeio Velho, Ribeiro \& Fantinel 1978 ou Andesito Rodeio Velho-Paim et al. 2000) são representadas por basaltos e andesitos de afinidade moderadamente alcalina a toleítica, com idades de aproximadamente $535 \mathrm{Ma}$ (Almeida et al. 2010).
O vulcanismo da Formação Acampamento Velho A organização estratigráfica desta formação tem sido sugerida por Wildner et al. (1999), Sommer et al. (1999, 2005), Almeida et al. (2002), sendo as melhores exposições desta unidade localizadas nos municípios gaúchos de Vila Nova do Sul (Platô da Ramada e Cerro Tupanci), Dom Pedrito (Platô do Taquarembó) e Caçapava do Sul (Passo do Salsinho) conforme ilustradas na figura 1.

As principais unidades são depósitos de fluxo piroclástico, principalmente ignimbritos, brechas vulcânicas, tufos de queda, normalmente cobertos por lavas riolíticas. Nos depósitos piroclásticos predominam os componentes juvenis, principalmente cristaloclastos de quartzo e feldspato alcalino, púmices e shards. Os litoclastos são mais abundantes nas porções basais dos depósitos e são principalmente conatos, embora sejam comuns fragmentos acidentais e acessórios originados das rochas encaixantes. A geometria dos depósitos e o grau de soldagem são variáveis, observando-se depósitos estratificados e parcialmente soldados até ignimbritos maciços com alto grau de soldagem. Nas lavas são comuns porções autobrechadas, foliadas e maciças.

Uma característica marcante da Formação Acampamento Velho é o predomínio dos depósitos ignimbríticos sub-horizontais que geraram platôs. Estes depósitos preservam feições típicas de processos piroclásticos primários, indicativas de fluxos de alta temperatura com grande quantidade de gases. Estas características associadas à frequente ocorrência de lavas e corpos hipabissais sugerem um vulcanismo subaéreo, relacionados possivelmente com caldeiras vulcânicas.

\section{FACIOLOGIA DOS DEPÓSITOS VULCÂNICOS}

Platô do Taquarembó O vulcanismo do Platô do Taquarembó estabeleceu-se sobre uma crosta continental granulítica (Complexo Granulítico Santa Maria Chico), sendo todos os registros investigados de natureza subaérea. $\mathrm{O}$ platô tem espessura estimada em cerca de 150 $\mathrm{m}$, sendo constituído na base por derrames básicos a intermediários shoshoníticos (Formação Hilário), seguidos por uma sucessão de rochas efusivas e piroclásticas ácidas, além de depósitos sedimentares vulcanogênicos (Formação Acampamento Velho). A fração vulcânica ácida da porção sul do Platô do Taquarembó, denominada por Sommer et al. (1999) de Sequência Vulcânica Ácida (SVA), pode ser dividida em dois eventos explosivos (ignimbritos) separados por unidades efusivas. Os depósitos de fluxos piroclásticos foram depositados em áreas com topografia horizontal, sem um controle efetivo da gravidade nos movimentos reomórficos. Os ignimbritos possuem um grau de soldagem elevado e são provavelmente equivalentes aos tipos maciços e estratificados (Sparks et al. 1973) (Fig. 2). No Platô do Taquarembó identificaram-se nos depósitos ignimbríticos, três unidades de resfriamento com espessuras inferiores a $30 \mathrm{~m}$.

O depósito piroclástico da unidade de resfriamento inferior é maciço e constitui possivelmente, uma 


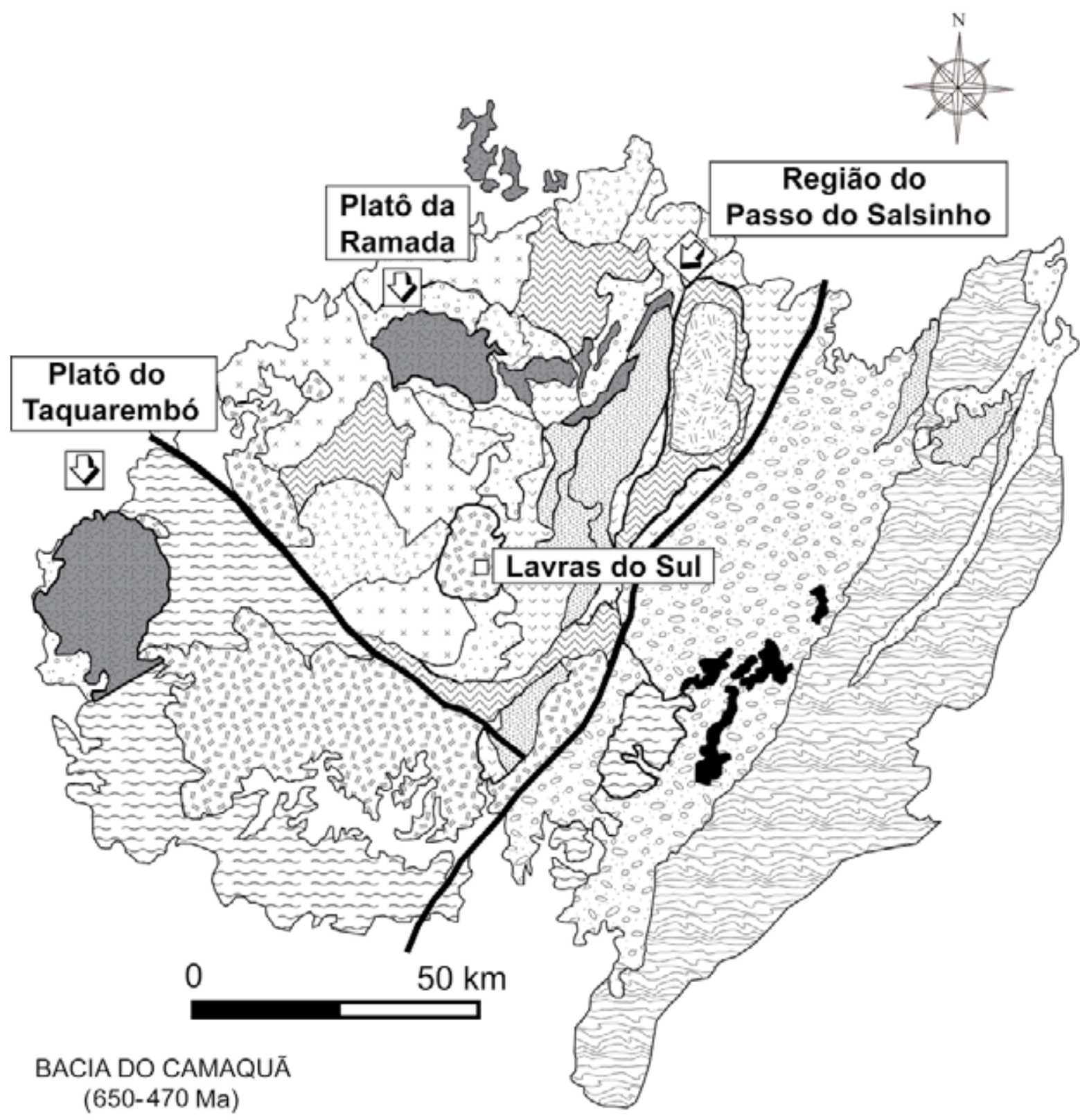

Grupo Camaquâ

Formaçăo Guaritas

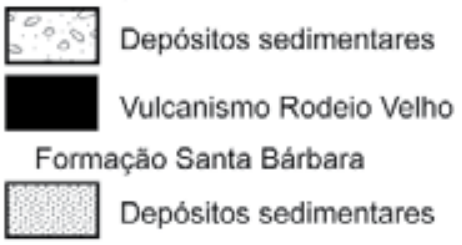

Grupo Bom Jardim

Formaçăo Acampamento Velho

Vulcanismo Acampamento Velho

Formaçăo Hilário

$\square$
$\cdots$

Formaçăo Maricá

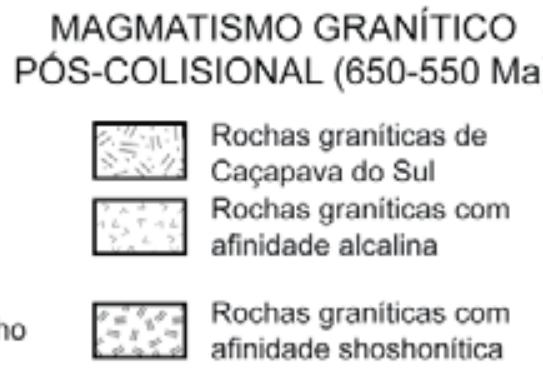

\section{MAGMATISMO GRANITICO OS-COLISIONAL (650-550 Ma)}

Rochas graníticas de Caçapava do Sul

Rochas graniticas com afinidade alcalina afinidade shoshonitica
ASSOCIAÇŌES DE ARCO MAGMÁTICO (800-700 Ma)

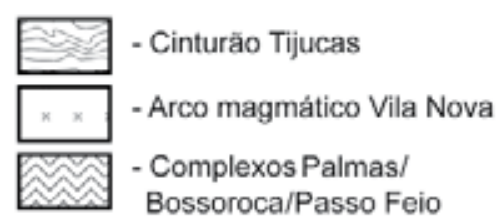

COMPLEXO GRANULITITICO

$\approx$ - Complexo Santa Maria Chico $(2,55 \mathrm{Ga})$

Depósitos sedimentares

Figura 1 - Esboço geológico da porção oeste do Escudo Sul-Rio-Grandense, com a localização dos Platôs da Ramada e Taquarembó. 
unidade deposicional (sensu Sparks et al. 1973, Sheridan 1979) relativamente homogênea com uma maior concentração de litoclastos na porção inferior, predominantemente de tamanho lápili de andesito (acidentais) e de riolito (conatos). A unidade é rica em púmices e shards fortemente achatados e possui uma soldagem de alto grau com feições indicativas de reomorfismo destacadas na porção de topo (Figs. 2 e 3).

Nas porções intermediárias do platô, os ignimbritos estão organizados em uma sucessão de camadas sub-horizontais, cujo elevado grau de soldagem dos depósitos dificulta a separação em unidades deposicionais de fluxo. A origem da estratificação pode estar vinculada à sucessão de unidades deposicionais distintas, que foram depositadas quase que simultaneamente, comportando-se como uma única unidade de resfriamento (Fig. 2).

A estratificação é marcada pela intercalação de níveis que contêm proporções diferentes na relação líticos-púmice. O nível basal desta porção intermediária possui uma espessura em torno de $1 \mathrm{~m}$ e é constituído dominantemente por shards e púmices com uma granulação fina $(<1 \mathrm{~mm})$. Este nível assemelha-se à camada 1 do fluxo piroclástico ideal proposto por Sparks et al. (1973) e pode representar um nível de ground surge (Sommer 1994). Esta camada é sucedida por um nível rico de fragmentos riolíticos vítreos a microcristalinos $(6,5$ até $20 \mathrm{~cm})$. Observa-se uma granodecrescência e um aumento em fragmentos vítreos e púmices para o

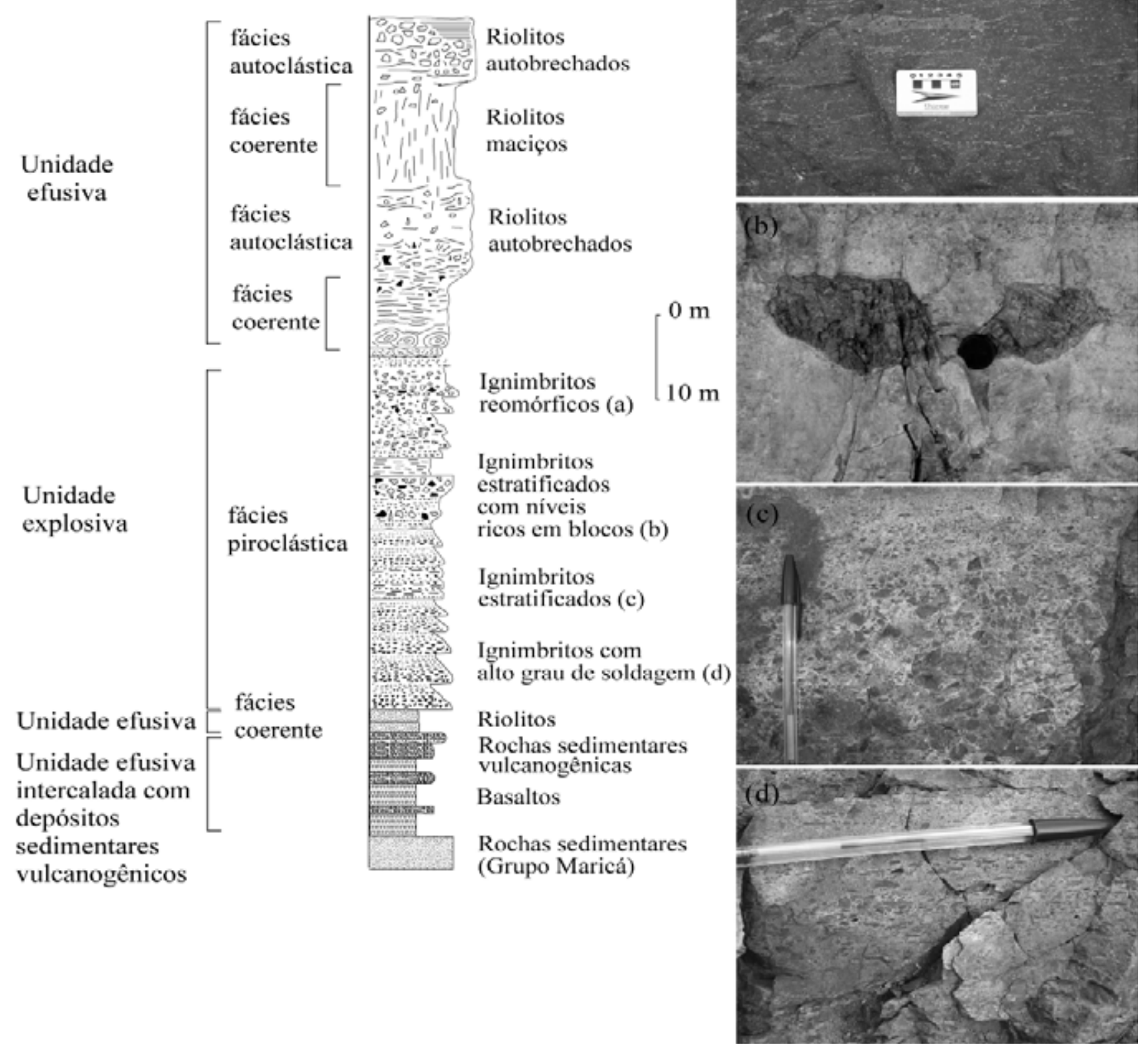

Figura 2 - Perfil estratigráfico esquemático dos depósitos vulcânicos do Platô do Taquarembó. 

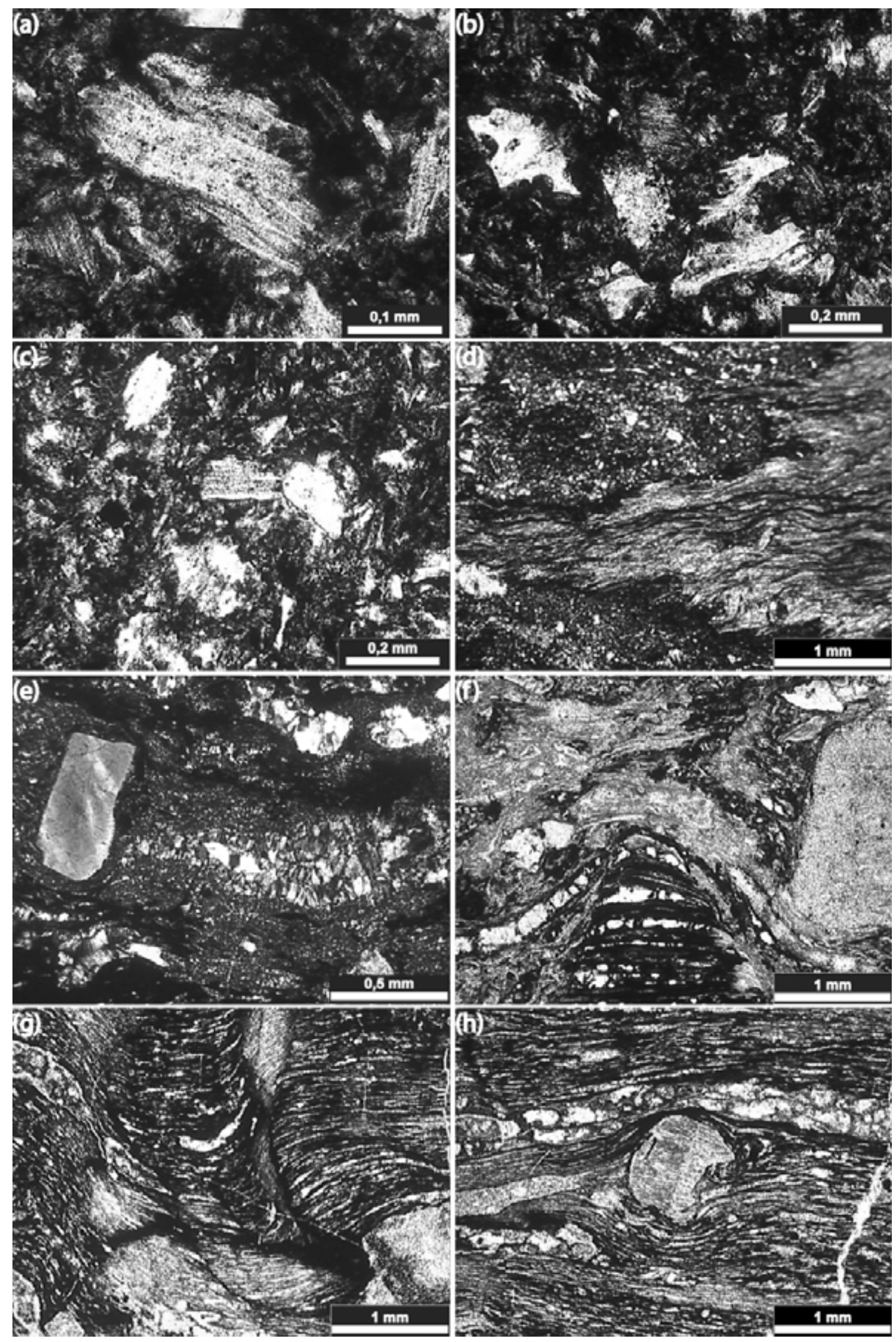

Figura 3 - Fotomicrografias representativas dos ignimbritos do Platô do Taquarembó com seus diferentes graus de soldagem: $(a-c)=$ shards e fragmento de púmice, em matriz de ignimbritos soldados, relacionado aos depósitos estratificados; (d) fiamme em ignimbrito soldado; (e) fragmentos de cristais, axiolitos e textura eutaxitica em ignimbrito soldado; (f) fragmentos de cristais e litoclasto em ignimbrito soldado com textura eutaxítica; ( $g$-h) textura parataxítica e fragmento de cristal rotacionado em ignimbritos reomórficos. 
topo da camada. Os vitroclastos estão desvitrificados, com fraturas perlíticas e deformados, com limites suavizados, o que sugere uma origem juvenil. Na matriz, observa-se a adesão e deformação de púmices e shards com hábitos cúspides em placa maciça e com bolhas (Fig. 3). O fato de que parte dos púmices mantém a morfologia original pode estar relacionado a uma concentração de litoclastos que dificultou o completo achatamento da fração juvenil.

Os ignimbritos reomórficos ocorrem na porção superior do depósito e possuem uma espessura em torno de $14 \mathrm{~m}$ e o contato é marcado por uma discordância erosiva. Diferentemente dos níveis subjacentes, estes possuem um aspecto homogêneo, "afanítico" com estruturas de fluxo marcadas por níveis onde se concentram os lithophysae (Fig. 2). Em lâmina delgada destaca-se o forte achatamento de vitroclastos e púmices, e uma textura parataxítica que contorna cristais de quartzo e feldspato alcalino, além de vitroclastos com texturas esferulítica e axiolítica (Fig. 3). Estruturas rotacionais em cristaloclastos são comuns associadas a feições com elevado estiramento, que é responsável pelo fraturamento e deslocamento de vitroclastos e cristais (Fig. 3).

Platô da Ramada O Platô da Ramada também possui vulcanitos shoshoníticos da Formação Hilário na base, sucedidos por vulcanitos da Formação Acampamento Velho, ambos de natureza subaérea, assentados sobre um embasamento composto por rochas sedimentares da Formação Maricá.

Todas as exposições de ignimbritos indicam um elevado grau de soldagem e uma espessura total em torno de $60 \mathrm{~m}$, depositados em áreas com topografia horizontal. Estes depósitos são sucedidos por lavas riolíticas, autobrechadas, foliadas e maciças (Sommer et al. 2005). De forma subordinada ocorrem lavas básicas intercaladas e intrusões rasas de composição diorítica a riolítica.

Os ignimbritos da base são enriquecidos em litoclastos, sendo a característica principal desta fácies, a pobre seleção (tamanho cinza até bloco). Ocorrem fragmentos conatos de riolitos e, subordinadamente, acidentais de granitoides, andesitos e arenitos, envolvidos por uma matriz com vitroclastos e púmices, com fenocristais de feldspato alcalino e quartzo (Fig. 4). Os ignimbritos que sucedem esta porção apresentam textura eutaxítica destacada e proporções semelhantes entre púmices, vitroclastos e litoclastos, cujas dimensões variam de cinza a lápili. $\mathrm{O}$ achatamento dos vitroclastos e púmices é responsável pela geração de fiamme. Parte dos púmices preserva parcialmente o hábito, sendo comum o tipo tubo. A matriz contorna cristaloclastos de feldspato alcalino e quartzo, geralmente com golfos de corrosão e litoclastos (Fig. 5). De forma subordinada, ocorrem ignimbritos ricos em cristais (40\%) como uma unidade de fluxo com geometria tabular.

Ignimbritos reomórficos concentram-se no topo, com a foliação marcada pelo forte estiramento de púmices e vitroclastos. Petrograficamente observa-se que o contato entre os constituintes foi obliterado, desaparecendo os limites externos dos fragmentos. Raros cristaloclastos com estruturas rotacionais e fiamme com elevado grau de estiramento, transformados em esferulitos e axiolitos, são envolvidos por matriz com textura parataxítica (Fig. 5). Agregados quartzo-feldspáticos com textura sacaroide constituem, provavelmente, sublimados da fase vapor.

\section{DADOS DE LITOQUÍMICA, TEMPERATURA E VISCOSIDADE}

Litoquímica As rochas ácidas do vulcanismo Acampamento Velho geralmente têm teores de $\mathrm{SiO}_{2}$ superiores a $70 \mathrm{wt} \%$ e razões $\mathrm{FeO}^{\mathrm{t}} /\left(\mathrm{FeO}^{\mathrm{t}}+\mathrm{MgO}\right)$ maiores que 0,9, típicos de riolitos de séries alcalinas (Ewart 1979). Apresentam predominantemente um caráter metaluminoso a peralcalino comendí́tico (MacDonald 1974, Le Maitre 2002), embora rochas subalcalinas sejam também observadas (Wildner et al. 1999, Sommer et al. 2005, Sommer et al. 2006, Lima et al. 2007). O caráter peralcalino predominante nas rochas ácidas é também sugerido pelos elevados teores de $\mathrm{Zr}$ (Leat et al. 1986). Os elementos traços nos riolitos exibem padrões similares aos das rochas graníticas de ambiente intraplaca $\mathrm{e}$ a elevada razão $\mathrm{Ce} / \mathrm{Nb}$ assemelha-se às das associações magmáticas pós-orogênicas (Leat et al. 1986). Os padrões de ETR são típicos de séries alcalinas com enriquecimento de ETRL em relação aos ETRP.

A origem deste magmatismo é assumida por muitos autores como de fontes mantélicas e, dados isotópicos de $\mathrm{Rb}, \mathrm{Sr}, \mathrm{Sm}$ e $\mathrm{Nd}$ aliados à geoquímica de elementos traços em rochas do Platô do Taquarembó sugerem uma fonte do tipo EM1 (Gastal \& Lafon 1998, Wildner et al. 1999, Chemale et al. 1999), com valores de $\varepsilon N d$ variando entre $-15,78$ e $-17,48$, e razões iniciais ${ }^{87} \mathrm{Sr} /{ }^{86} \mathrm{Sr}$ em torno de 0,7045 .

Temperatura e Viscosidade As temperaturas de cristalização e a viscosidade são estimadas a partir da composição química das rochas, sendo estes parâmetros físicos necessários para a discussão dos mecanismos de soldagem. Na Formação Acampamento Velho, a determinação destes parâmetros fundamentou-se na composição química de ignimbritos e reoignimbritos dos platôs do Taquarembó e da Ramada (Tab. 1).

TEMPERATURA Os dados de temperatura foram estimados a partir do conteúdo de elementos maiores e $\mathrm{Zr}$, conforme o método sugerido por Watson (1979) e Watson \& Harrison (1983). Adicionalmente calculou-se a temperatura liquidus, seguindo a sistemática de Sisson \& Grove (1993).

Dados de saturação de zircão nos ignimbritos dos platôs do Taquarembó e da Ramada indicam um intervalo de temperatura entre 870 e $978^{\circ} \mathrm{C}$ (Tab. 1), próximos aos obtidos para a temperatura liquidus (903$953^{\circ} \mathrm{C}$ ). Estes valores são um pouco mais elevados do 

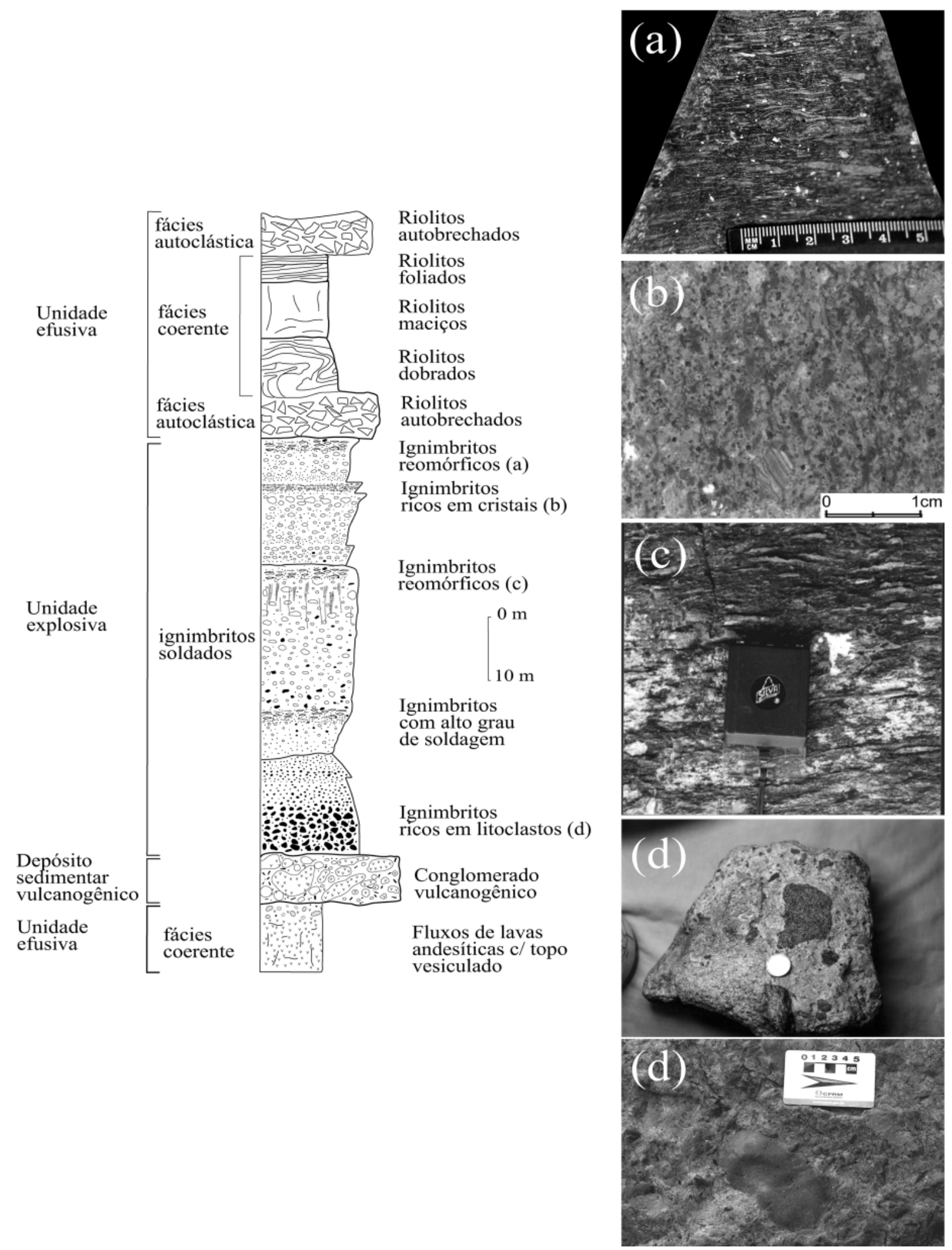

Figura 4 - Perfil estratigráfico esquemático dos depósitos vulcânicos do Platô da Ramada.

que os obtidos por Streck e Grunder (1997) no riolito Rattlesnake Tuff de afinidade metaluminosa a levemente peralcalina. Valores médios de $850 \pm 50^{\circ} \mathrm{C}$ para a temperatura de cristalização do zircão foram obtidos por Pierosan et al. (2010) em ignimbritos ácidos metaluminosos do Grupo Iricoumé. Estes resultados são próximos aos obtidos em riolitos e granitos representativos do magmatismo tipo A (Clemens et al. 1986, King et al. 1997, Dall'Agnol et al. 1999, Hergt et al. 2007). Dados experimentais obtidos por Patiño Douce 

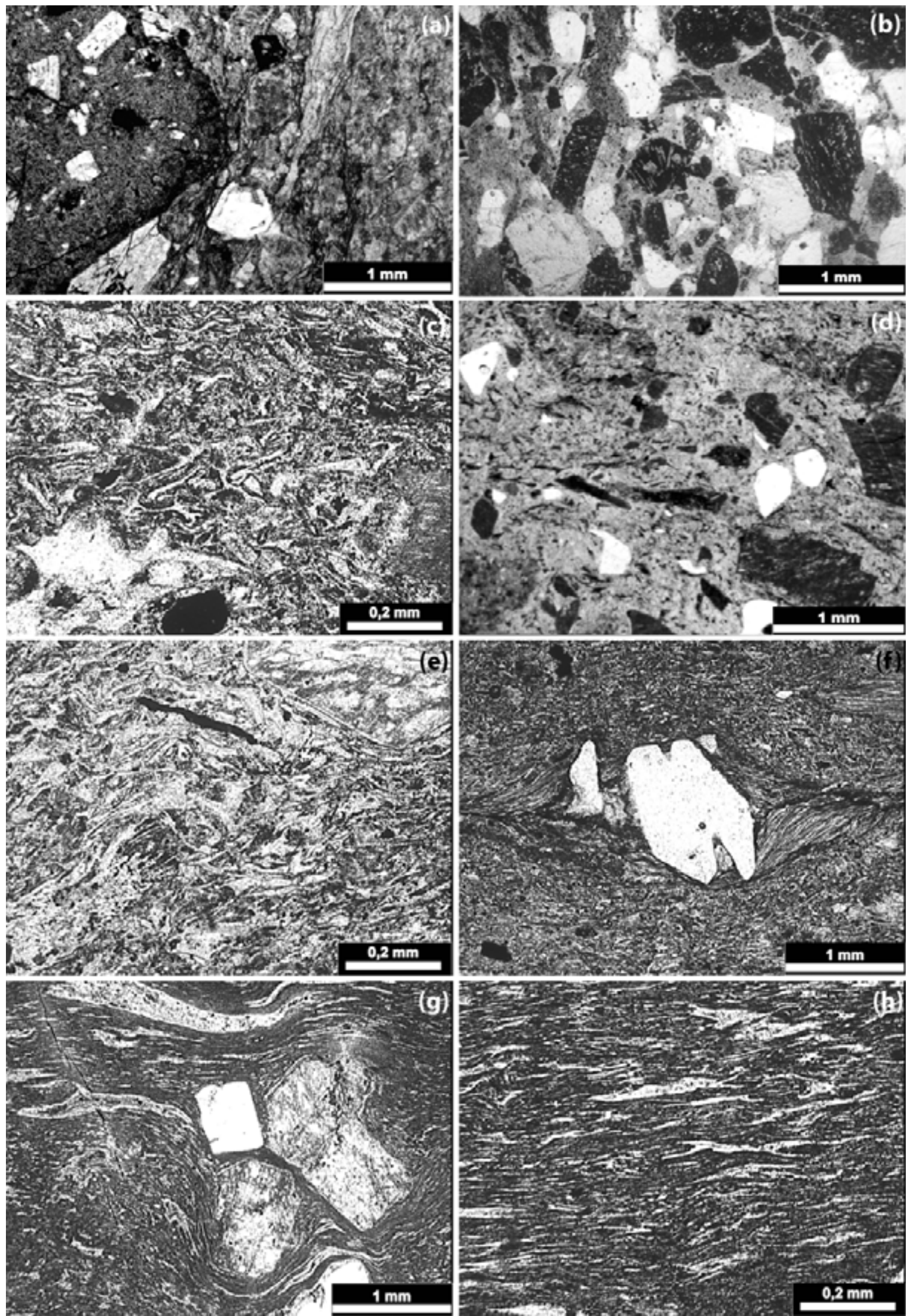

Figura 5 - Fotomicrografias representativas dos ignimbritos do Platô da Ramada com seus diferentes graus de soldagem: (a) ignimbrito soldado, rico em litoclastos, com fragmento de riolito; (b) ignimbrito soldado rico em cristais; (c) shards e fragmentos de púmices em ignimbrito soldado; (d) fragmento de cristais e púmices em ignimbrito soldado com textura eutaxítica; (e) fragmento de cristal, púmices e shards achatados em ignimbrito soldado; (f) fragmentos de cristais envolvidos por púmice estirado em ignimbrito reomórfico; $(g$ - $h$ ) fragmentos de cristais e púmices em ignimbrito reomórfico com textura parataxítica. 
(1997) indicam temperaturas em torno de $950^{\circ} \mathrm{C}$ para a geração de magmas do tipo A.

A comparação entre as temperaturas calculadas (Tab.1 e Fig. 6) indica valores maiores para o Platô do Taquarembó $\left(870-978^{\circ} \mathrm{C}\right)$ que as estimadas para o Platô da Ramada $\left(850-946^{\circ} \mathrm{C}\right)$. Observa-se ainda, que no topo de ambos os platôs, as temperaturas mais elevadas foram obtidas em reoignimbritos $\left(\right.$ média $=945^{\circ} \mathrm{C}$ ), o que é coerente com os conteúdos mais elevados de $\mathrm{Zr}$ nestes litotipos.

VISCOSIDADE Os dados de viscosidade efetiva, obtidos para as rochas da Formação Acampamento Velho, foram calculados a partir dos dados de elementos maiores, utilizando-se a estimativa de Bottinga \& Weill (1972), que envolve a equação de Einstein-Roscoe (McBirney \& Murase 1984), considerando-se a estimativa percentual de cristais/vesículas e o seu diâmetro médio (Tab. 1).

Como parâmetro inicial assumiu-se uma condição anidra e os dados de temperatura foram estimados a partir do método de saturação de Zr (Watson 1979, Watson \& Harrison 1983, Hanchar \& Watson 2003). Petrograficamente estimou-se um volume de $5 \%$ de cristais com $1 \mathrm{~mm}$ de diâmetro médio para os reoignimbritos, ao passo que para os ignimbritos assumiu-se cerca de $30 \%$ de cristais com diâmetro médio de $3 \mathrm{~mm}$.

Os valores calculados para a viscosidade variam de $4,77 \times 10^{7}$ a $1,39 \times 10^{8} \mathrm{~Pa}$ s para os reoignimbritos, e $1,72 \times 10^{11}$ a $6,55 \times 10^{11}$ Pa s para os ignimbritos (Fig. 6). Estes resultados são similares aos obtidos no Ignimbrito Campanian (Giordano et al. 2006) e nos riolitos paleoproterozoicos do Grupo Iricoumé (Pierosan et al. 2010).

\section{DISCUSSÃO}

Temperatura, $\mathrm{H}_{2} \mathrm{O}$ e Espessura de Fluxo Dados experimentais para sistemas riolíticos em condições anidras indicam temperaturas mínimas de soldagem entre 900 e $1.000^{\circ} \mathrm{C}$ (Gründer et al. 2005), sendo estas superiores às observadas em sistemas naturais. Variações no conteúdo de água podem reduzir a temperatura mínima de soldagem para $600^{\circ} \mathrm{C}$ em sistemas silicosos metaluminosos (Quane \& Russell 2005). De acordo com Dingwell \& Webb (1990), esta temperatura representa o limite cinético entre um "líquido" (sistema viscoso) e um sólido (elástico) em resposta ao esforço mecânico aplicado. Acima da temperatura de transição, as partículas serão viscosamente deformadas permitindo

Tabela 1 - Dados de litoquímica (maiores em \% peso e traços em ppm) e resultados de temperaturas e viscosidade para amostras representativas de reoignimbritos (reom) e ignimbritos (ign) da Formação Acampamento Velho. Legenda: amostras $C C=$ Platô do Taquarembó; amostras $R M=$ Platô da Ramada.

\begin{tabular}{|c|c|c|c|c|c|c|c|c|c|c|c|c|}
\hline & $\mathrm{CCO} 2$ & $\mathrm{CC} 08 \mathrm{~A}$ & $\mathrm{CC} 12 \mathrm{~A}$ & CC188 & $\mathrm{CC} 25$ & $\mathrm{CC} 74$ & RM23A & RM22 & RM86A & RM52 & RM111 & RM36 \\
\hline & Reom & Reom & Reom & Ign & Ign & Ign & Reom & Reom & Reom & Ign & Ign & Ign \\
\hline $\mathrm{SiO}_{2}$ & 74,09 & 76,25 & 77,59 & 72,61 & 75,42 & 72,55 & 72,54 & 72,89 & 73,27 & 75,55 & 73,46 & 71,50 \\
\hline $\mathrm{TiO}_{2}$ & 0,3 & 0,23 & 0,22 & 0,41 & 0,31 & 0,20 & 0,23 & 0,20 & 0,13 & 0,15 & 0,11 & 0,11 \\
\hline $\mathrm{Al}_{2} \mathrm{O}_{3}$ & 11,31 & 10,88 & 10,31 & 12,72 & 11,01 & 12,84 & 11,86 & 12,72 & 12,10 & 11,44 & 11,65 & 13,39 \\
\hline $\mathrm{FeO}_{\mathrm{t}}$ & 3,47 & 3,72 & 3,66 & 3,91 & 3,60 & 3,18 & 2,83 & 2,35 & 1,95 & 1,13 & 1,84 & 1,40 \\
\hline $\mathrm{MnO}$ & 0,03 & 0,02 & 0,01 & 0,04 & 0,10 & 0,07 & 0,05 & 0,02 & 0,02 & 0,02 & 0,04 & 0,02 \\
\hline $\mathrm{MgO}$ & 0,44 & 0,49 & 0,46 & 0,10 & 0,10 & 0,07 & 0,24 & 0,10 & 0,08 & 0,07 & 0,07 & 0,14 \\
\hline $\mathrm{CaO}$ & 0,11 & 0,09 & 0,13 & 0,27 & 0,15 & 0,51 & 0,76 & 0,06 & 0,02 & 0,05 & 0,29 & 0,58 \\
\hline $\mathrm{Na}_{2} \mathrm{O}$ & 4,72 & 3,03 & 3,47 & 4,31 & 3,71 & 4,31 & 3,72 & 3,60 & 3,65 & 3,53 & 4,35 & 4,66 \\
\hline $\mathrm{K}_{2} \mathrm{O}$ & 4,26 & 4,25 & 3,96 & 3,90 & 4,17 & 4,19 & 5,11 & 5,53 & 5,73 & 5,06 & 4,95 & 4,68 \\
\hline $\mathrm{P}_{2} \mathrm{O}_{5}$ & 0,1 & 0,02 & 0,01 & 0,00 & 0,01 & 0,01 & 0,04 & 0,04 & 0,01 & 0,04 & 0,02 & 0,03 \\
\hline LOI & 0,21 & 0,75 & 0,37 & 0,4 & 0,87 & 1,14 & 1,90 & 1,30 & 1,00 & 1,00 & 1,00 & 1,10 \\
\hline Total & 99,29 & 100,02 & 100,45 & 99,01 & 99,79 & 99,23 & 99,6 & 99,07 & 98,16 & 98,17 & 97,98 & 97,77 \\
\hline IAGP & 1,09 & 0,88 & 0,97 & 0,89 & 0,96 & 0,91 & 0,98 & 0,93 & 1,01 & 0,98 & 1,07 & 0,95 \\
\hline $\mathrm{Ba}$ & 73 & 119 & 157 & 548 & 122 & 477 & 272 & 288 & 133 & 181 & 162 & 143 \\
\hline $\mathrm{Rb}$ & 160 & 118 & 146 & 86 & 136 & 124 & 99 & 113 & 141 & 138 & 151 & 250 \\
\hline $\mathrm{Sr}$ & 30 & 34 & 40 & 23 & 30 & 48 & 25 & 20 & 10 & 22 & 10 & 20 \\
\hline $\mathrm{Zr}$ & 719 & 801 & 781 & 544 & 684 & 360 & 682 & 634 & 511 & 570 & 637 & 385 \\
\hline T Sat $\mathrm{Zr}(\mathrm{M})\left({ }^{\circ} \mathrm{C}\right)$ & 936 & 978 & 963 & 923 & 947 & 870 & 920 & 943 & 913 & 928 & 920 & 870 \\
\hline $\mathrm{T}$ líquido $\left({ }^{\circ} \mathrm{C}\right)$ & 935 & 931 & 939 & 920 & 929 & 931 & 952 & 922 & 886 & 884 & 879 & 904 \\
\hline $\begin{array}{l}\text { Viscosidade } \\
\left(\mathrm{Pa} \mathrm{s}^{-1}\right)\end{array}$ & $\begin{array}{l}1,25 \\
\times 10^{8}\end{array}$ & $\begin{array}{l}4,77 \\
\times 10^{7}\end{array}$ & $\begin{array}{l}7,43 \\
\times 10^{7}\end{array}$ & $\begin{array}{l}2,43 \\
\times 10^{11}\end{array}$ & $\begin{array}{c}1,72 \\
\times 10^{11}\end{array}$ & $\begin{array}{l}5,66 \\
\times 10^{11}\end{array}$ & $\begin{array}{l}9,82 \\
\times 10^{7}\end{array}$ & $\begin{array}{l}8,02 \\
\times 10^{7}\end{array}$ & $\begin{array}{l}1,39 \\
\times 10^{8}\end{array}$ & $\begin{array}{c}2,55 \\
\times 10^{11}\end{array}$ & $\begin{array}{l}2,87 \\
\times 10^{11}\end{array}$ & $\begin{array}{c}6,55 \\
\times 10^{11}\end{array}$ \\
\hline
\end{tabular}



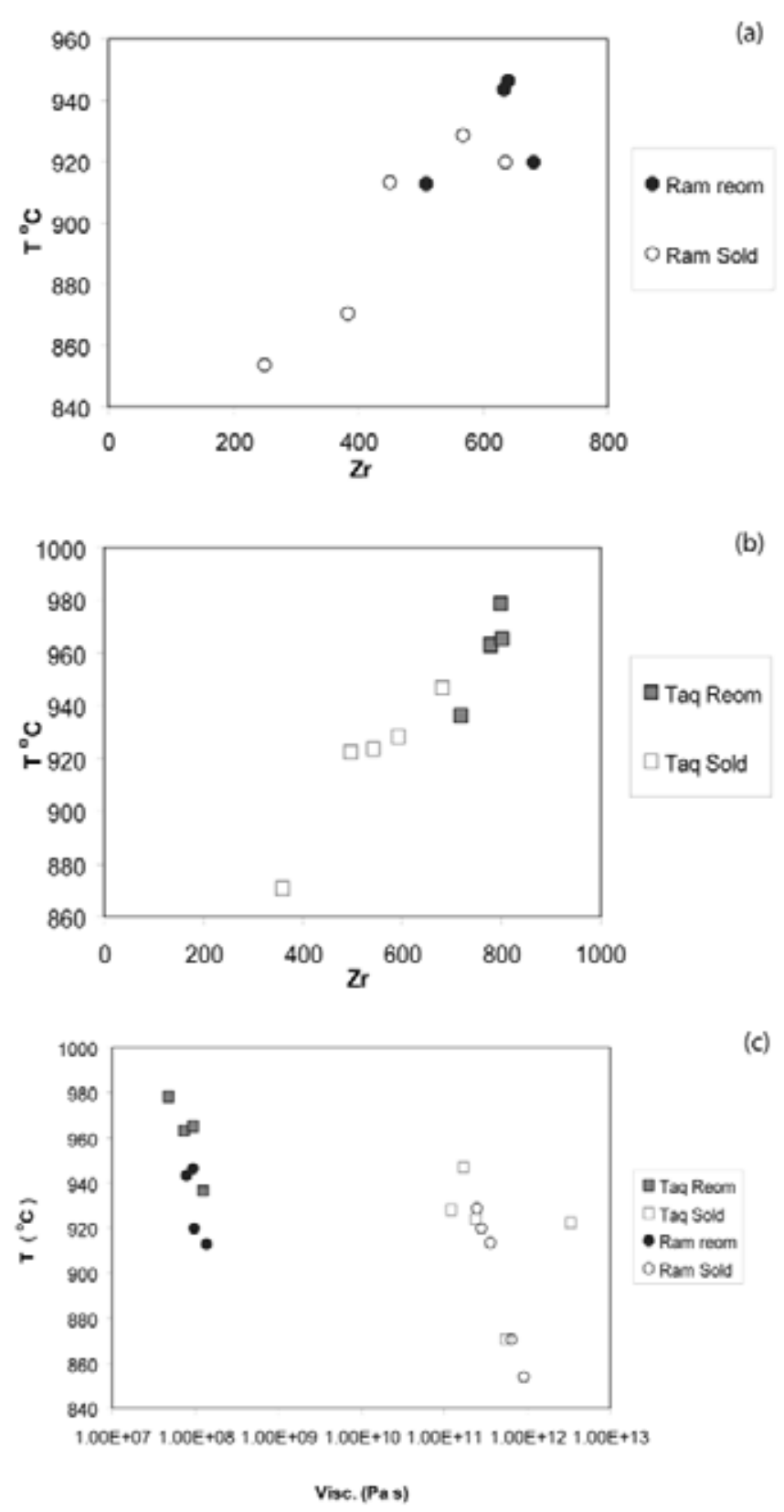

Figura 6 - Diagramas com os valores calculados de temperatura em relação aos teores de $\mathrm{Zr}$ (ppm): (a) Platô da Ramada; (b) Platô do Taquarembó. Diagrama com valores de vicosidade em relação à temperatura para os reoignimbritos e ignimbritos dos platôs do Taquarembó e Ramada. Legenda: Taq reom e Ram reom = reoignimbritos dos platôs do Taquarembó (Taq) e Ramada (Ram); Taq sold e Ram sold = ignimbritos dos platôs do Taquarembó (Taq) e Ramada (Ram).

a soldagem, e abaixo desta temperatura, a soldagem é inibida. Em sistemas peralcalinos a diferença de temperatura entre o limite viscoso e o elástico pode ser da ordem de $100^{\circ} \mathrm{C}$ (Llambias 2003). Aspectos composicionais são, portanto, importantes no entendimento da origem da soldagem, considerando-se a temperatura de transição do vidro para cada sistema químico.
Os depósitos dos platôs do Taquarembó e Ramada possuem um elevado grau de soldagem, indicativo de temperaturas superiores à mínima, sendo os valores obtidos próximos aos discutidos por Gründer et al. (2005) para os ignimbritos Rattlesnake Tuff de mesma afinidade química. As temperaturas mais elevadas são observadas nos reoignimbritos com peralcalinidade em torno da unidade e, consequentemente, apresentam uma viscosidade menor, o que explicaria o reomorfismo observado nesta fácies.

A influência da compactação e do conteúdo de água na soldagem de ignimbritos, associada com a temperatura, foi também avaliada de forma experimental por Gründer et al. (2005). A pressão de carga exercida pela acumulação de piroclastos durante o fluxo tem sido assumida como um dos principais fatores responsáveis pela compactação e expulsão de gases intersticiais (Smith 1960a). A água é outro fator importante na soldagem e a presença desta nos piroclásticos vítreos reduz a viscosidade promovendo a deformação viscosa (Shaw 1972). De acordo com Dingwell et al. (1996), baixos conteúdos de $\mathrm{H}_{2} \mathrm{O}$ são típicos em vidro riolíticos e conteúdos da ordem de $0,2 \%$ a $0,4 \%$ seriam suficientes para causar a supersaturação e a liberação de voláteis em magmas riolíticos durante a ascensão, reduzindo substancialmente a viscosidade do magma e, portanto, inibindo a rápida perda desta fase. De acordo com estes autores, uma carga litostática superior a 1 MPa s $\left(600^{\circ} \mathrm{C}, 0,2 \% \mathrm{H}_{2} \mathrm{O}\right)$ seria necessária para gerar a soldagem, ou seja, maior que $40 \mathrm{~m}$ de espessura de um depósito. Pressões bem superiores (5 MPa s) sob mesmas condições de temperatura e conteúdos de $\mathrm{H}_{2} \mathrm{O}$ geraram experimentalmente texturas de um elevado grau de soldagem.

As espessuras das unidades de resfriamento são inferiores a $30 \mathrm{~m}$ no Platô do Taquarembó, porém, a elevada soldagem e a presença de cristais reabsorvidos e de quartzo cristalizado são feições típicas de fluxos gerados em alta temperatura (Schmincke 1974). Portanto, a carga litostática não explica o elevado grau de soldagem e reomorfismo observados neste platô.

Nas unidades de resfriamento do Platô da Ramada, estas mesmas características são observadas. Nas porções superiores dos platôs do Taquarembó e Ramada concentram-se reoignimbritos com texturas parataxítica e micropoiquilítica, com vesículas estiradas preenchidas por quartzo microcristalino. De acordo com Branney \& Kokelaar (1992) e Freundt (1998) estas feições indicam a geração de depósitos por um regime deposicional denominado de não particulado, sendo as partículas vítreas homogeneizadas durante o fluxo, eliminando parcial a completamente a textura clástica primária.

Modelo de Soldagem A diversidade de depósitos piroclásticos de alto grau de soldagem fez com que diferentes modelos tenham sido propostos para a origem e colocação destes fluxos de alta temperatura (Fig. 7). Texturas piroclásticas com forte deformação, de acordo com Schmincke \& Swanson (1967), são geradas a 

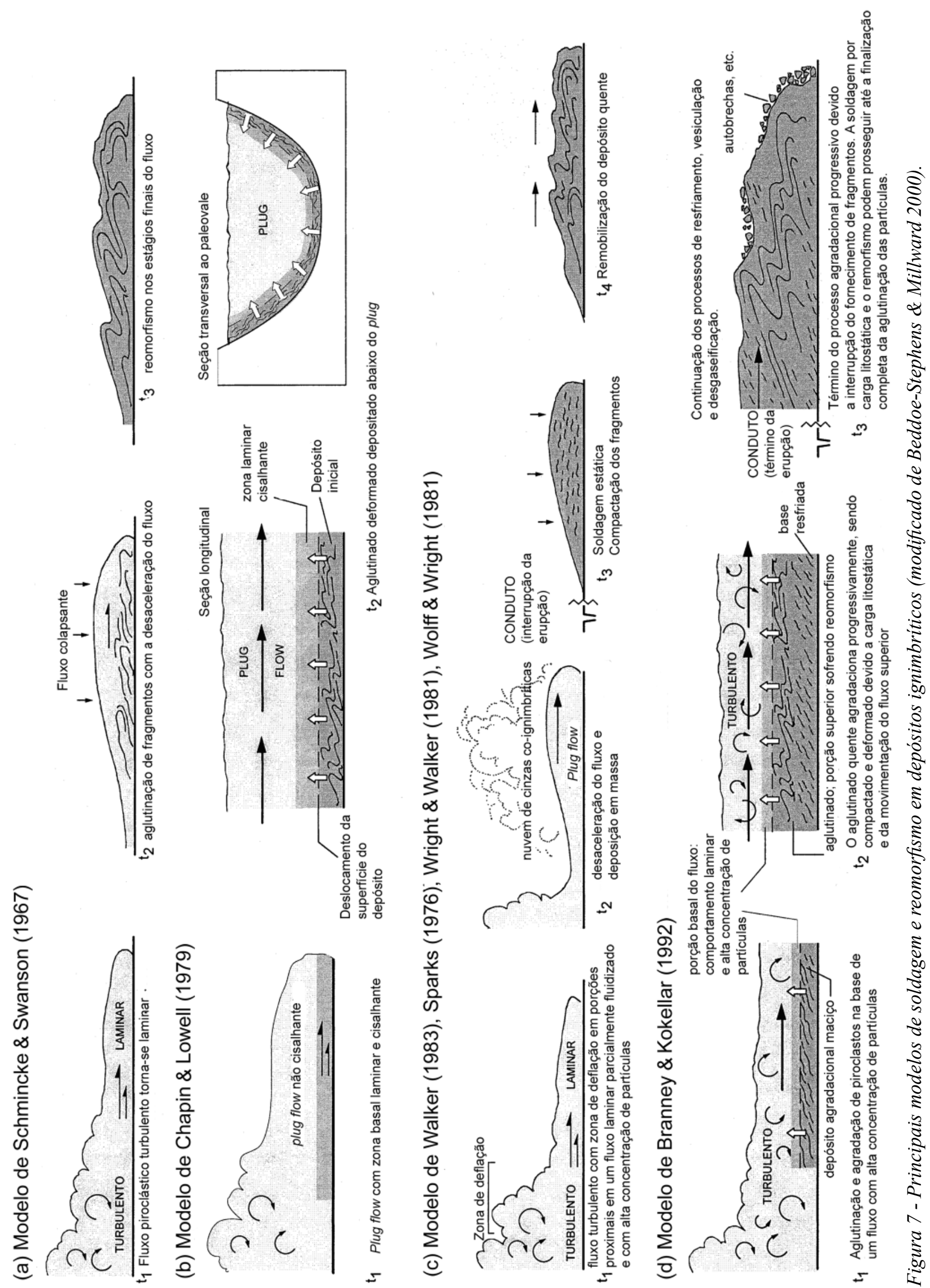
partir de fluxo laminar viscoso em movimento, onde o aglutinado de partículas piroclásticas quentes é gradualmente achatado e deformado à medida que este fluxo desacelera em massa (Fig. 7a). Assim, a rápida soldagem e o reomorfismo são anteriores e independentes da soldagem e resfriamento pós-deposicional. Um modelo semelhante foi proposto por Chapin \& Lowell (1979), onde a aglutinação e deformação das partículas piroclásticas ocorrem durante a colocação inicial de um fluxo denso ( $\mathrm{plug}$ flow), sendo estes processos progressivamente acentuados nas camadas limites da base e laterais durante o preenchimento de um vale (Fig. 7b). Wolff \& Wright (1981) postulam que a soldagem e o reomorfismo se estabelecem após o transporte e deposição do fluxo piroclástico (Fig. 7c). Neste modelo, como no de Schmincke \& Swanson (1967), é necessário que o transporte do fluxo piroclástico seja interrompido em massa, sendo as complexas mudanças verticais, no tamanho de grão e composição, interpretadas como deposição de sucessivos fluxos piroclásticos. Branney \& Kokelaar (1992, 1997, 2002) descartam estes modelos de interrupção em massa do movimento do fluxo e propõem que a deposição de ignimbritos espessos está geralmente relacionada à rápida e contínua agradação de piroclastos, sendo as mudanças de composição e de constituintes da erupção registradas no zoneamento vertical do ignimbrito (Fig. 7f). Segundo estes autores, os depósitos de lápili tufos maciços são gerados por processos agradacionais progressivos a partir de uma camada basal com alta concentração, na relação piroclastos versus voláteis, independente do conteúdo de partículas e maior grau de turbulência na corrente. Neste modelo, o grau elevado de soldagem e reomorfismo não se restringe a fluxos muito densos (plug flow) colocados em vales. As mudanças verticais na intensidade de soldagem indicam mudança na viscosidade (temperatura, composição, conteúdo voláteis) dos clastos a partir da base que vai sendo agradada durante o fluxo. A deformação do depósito pode continuar após o suprimento de material piroclástico. O modelo de aglutinação, durante o processo agradacional progressivo, tem a vantagem de explicar algumas mudanças verticais no tamanho do grão, da composição e intensidade de soldagem em um mesmo fluxo piroclástico.

No presente trabalho assume-se o modelo agradacional progressivo (Branney \& Kokelaar 1992) como o mais indicado para explicar as variações verticais no tamanho de grão, tipo de constituintes, grau de soldagem e o aumento dos conteúdos de $\mathrm{Zr}$ em direção ao topo dos platôs (reoignimbritos). A transição dos ignimbritos para reoignimbritos sugere a permanência de temperaturas altas em todo o fluxo e a concentração de fragmentos com menor viscosidade no topo. Pelo modelo assumido, a elevada soldagem e o reomorfismo desenvolveram-se durante o transporte e deposição do fluxo em uma paleotopografia relativamente plana. Processos pós-deposicionais de soldagem podem também ter ocorrido, porém em escala muito subordinada, sendo poucas e localizadas as evidências da atuação da carga litostática como agente importante na soldagem dos depósitos.
CONCLUSÕES Os depósitos vulcânicos neoproterozoicos da Formação Acampamento Velho estabeleceram-se no Escudo Sul-Rio-Grandense em condições subaéreas. Registros deste vulcanismo são encontrados em platôs no sudoeste do Rio Grande do Sul, os quais são constituídos por ignimbritos e efusivas ácidas. A afinidade geoquímica deste magmatismo é compatível com séries alcalinas sódicas metaluminosas a peralcalinas, que são associadas aos estágios pós-colisionais. O elevado grau de soldagem destes depósitos e o reomorfismo de parte destes indicam pouca perda de calor entre a origem e o emplaçamento destes fluxos, comum em colunas de erupções baixas. Nestes depósitos dominam expressivamente fragmentos juvenis, como púmices, shards e fragmentos vítreos maciços. Os cálculos de temperaturas pré-eruptivas obtidos na saturação em zircão mostram valores elevados, sendo o grau de soldagem observado nos ignimbritos da Formação Acampamento Velho indicativo de temperaturas superiores a mínima. Nas porções intermediárias e de base são observadas variações verticais no tamanho dos clastos e tipos de fragmentos, sendo estas associadas a uma pronunciada textura eutaxítica, que mantém parte do aspecto clástico do depósito. Nas porções superiores concentram-se reoignimbritos com texturas parataxítica e micropoiquilítica, geradas pela intensa deformação de púmices e fragmentos vítreos associada à desvitrificação em altas temperaturas. Vesículas estiradas, preenchidas com quartzo microcristalino, podem ter sido geradas pela migração lateral dos voláteis entre os planos de fluxo. Os dados geoquímicos indicam que os conteúdos de $\mathrm{Zr}$ crescem em direção ao topo da sequência piroclástica. Esta variação indica também o aumento da peralcalinidade que favorece a redução da viscosidade dos clastos. Não é descartada a participação da água como um fator adicional na redução da viscosidade, se considerada a elevada concentração de púmices nos reoignimbritos e a liberação de voláteis durante a deformação.

O elevado grau de soldagem e o reomorfismo dos depósitos piroclásticos dos platôs do Taquarembó e Ramada podem ser explicados pelo modelo agradacional progressivo, portanto, são feições sin-deposicionais. Adicionalmente, a espessura dos depósitos piroclásticos dos platôs estudados não favorece a hipótese da carga litostática ter atuado como agente importante na soldagem e reomorfismo.

Platôs vulcânicos como o da Ramada e do Taquarembó, cuja origem está vinculada a fluxos piroclásticos de alta temperatura, ricos em fragmentos juvenis e gerados a baixas colunas de erupção, são, em geral, interpretados como depósitos ignimbríticos extracaldeira.

Agradecimentos Ao CNPq pelas bolsas de produtividade e pelo apoio financeiro (CNPq: 306616/2006$8, \quad 306142 / 2006-6, \quad 303584 / 2009-2, \quad 473683 / 2007$, 5470641/2008-8, 470203/2007-2 e 303038/2009-8). Ao IGEO/UFRGS pela logística. 


\section{Referências}

Almeida R.P., Janikian L., Fragoso-Cesar A.R.S., Fambrini G.L. 2010. The Ediacaran to Cambrian Rift System of Southeastern South America: Tectonic Implications. The Journal of Geology, 118:145-161.

Almeida D.P.M., Zerfass H., Lima L. 1998. Estratigrafia das rochas vulcânicas da Formação Acampamento Velho (meso-cambriano a eo-ordoviciano) na região dos Cerros do Bugio e Perau (Caçapava do Sul, RS/Brasil). In: Congreso Uruguayo de Geologia, 2, Ext. abstracts, p. 92-95.

Almeida D.P.M., Zerfass H., Basei M.A., Petry K., Gomes C.H. 2002. The Acampamento Velho Formation, a Lower Cambrian Bimodal Volcanic Package: Geochemical and Stratigraphic Studies from the Cerro do Bugio, Perau and Serra de Santa Bárbara (Caçapava do Sul, Rio Grande do Sul, RS - Brazil). Gondwana Research, 5(3):721-733.

Beddoe-Stephens B. \& Millward D. 2000. Very densely welded, rheomorphic ignimbrites of homogeneous intermediate calc-alkaline composition from the English Lake District. Geol. Mag., 137(2):155-173.

Bonin B. 2004. Do coeval mafic and felsic magmas in postcollisional to within-plate regimes necessarily imply two contrasting, mantle and crustal, sources? A review. Lithos, 78:1-24.

Bottinga Y. \& Weill D.F. 1972. The viscosity of magmatic silicate liquids: a model for calculation. Am. J. Sci., 272:438-75

Boyd F.R. 1961. Welded tuffs and flows in the rhyolite plateau of Yellowstone Park, Wyoming. Geol. Soc. Am. Bull., 72:387-426.

Branney M.J. \& Kokelaar P. 1992. A Reappraisal of ignimbrite emplacement: progressive aggradation and changes from particulate to non-particulate flow during emplacement of high-grade ignimbrite. Bulletin of Volcanology, 54:504-520.

Branney M.J. \& Kokelaar B.P. 1997. Giant bed from a sustained catastrophic density current flowing over topography: Acatlan ignimbrite, Mexico. Geology, 25:115-118.

Branney M.J. \& Kokelaar B.P. 2002. Pyroclastic density currents and the sedimentation of ignimbrites. Geological Society of London, Memoirs, 27:1-152.

Branney M.J., Kokelaar B.P., McConnell B.J. 1992. The Bad Step Tuff: a lava-like rheomorphic ignimbrite in a calc-alkaline piecemeal caldera, English Lake District. Bulletin of Volcanology, 53:187-199.

Brito Neves B.B. \& Cordani U.G. 1991. Tectonic evolution of South America during Late Proterozoic. Precambrian Research, 53:23-40.

Chapin C.E. \& Lowell G.R. 1979. Primary and secondary flow structures in ash-flow tuffs of the Gribbles run paleovalley, Central Colorado. Geology Society of America Special Paper. 180:137-154.

Chemale Jr. F. 2000. Evolução Geológica do Escudo Sul-riograndense. In: Holz, M. \& De Ros, L. F. (ed.). Geologia do Rio Grande do Sul. Porto Alegre, CIGO/UFRGS, p. 13-52.

Chemale Jr. F., Wildner W., Lima E.F., Van Schmus W.R. 1999. Isotopic studies of Brasiliano retro-arc magmatism in Southern Brazil. In: SBG, Simpósio sobre Vulcanismo e Ambientes Associados, 1, Abstracts, p. 57.

Clemens J.D., Holloway J.R., White A.J.R. 1986. Origin of an A-type granite: experimental constraints. Am. Min., 71:317-324.

Dall'Agnol R., Scaillet B., Pichavant M. 1999. An experimental study of a Lower Proterozoic A-type granite from the eastern Amazonian Craton, Brazil. Journ. of Petr., 40(11):1673-1698.

Dingwell D.B. \& Webb S.L. 1990. Relaxation in silicate melts. Eur. J. Mineral., 2:427-449.

Dingwell D.B., Romano C., Hess K.U. 1996. The effect of water on the viscosity of haplogranite melt under P-T-X conditions relevant to silicic volcanism. Contrib. Mineral. Petrol., 124:19-28.

Ekren E.B., Mc Intyre D.H., Bennett E.H., 1984. Hightemperature, large-volume, lavalike ash-flow tuff without calderas in southwestern Idaho. U. S. Geol. Surv. Prof. Pap., 1272:1 -76.

Ewart A. 1979. A review of the mineralogy and chemistry of Tertiary-Recent dacitic, latitic, rhyolitic and related salic volcanic rocks. In: Baker F. (ed.). Trondhjemites, dacites and related rocks. Amsterdam, Elsevier, p. 113-121.

Freundt A. 1998. The formation of high-grade ignimbrites. I. Experiments on high- and low-concentration transport systems containing sticky particles. Bull. Volcanol., 59:414-435

Gastal M.C.P. \& Lafon J.M. 1998. Gênese e evolução dos granitóides metaluminosos de afinidade alcalina da porção oeste do escudo sul-rio-grandense: geoquímica e isótopos de $\mathrm{Rb}-\mathrm{Sr}$ e $\mathrm{Pb}-\mathrm{Pb}$. Revista Brasileira de Geociências, 28:11-28.

Giordano D., Mangiacapra A., Potuzak M., Russel J.K., Romano C., Dingwell D.B., Di Muro A. 2006. An expanded non-Arrhenian model for silicate melt viscosity: A treatment for matealuminous, peraluminous and peralkaline liquids. Chem. Geol., 229:42-56.

Gottsman J. \& Dingwell D.B. 2001. Cooling dynamics of spatter-fed phonolite obsidian flows on Teneriefe, Canary Islands. J. Volcanol. Geotherm. Res., 105:323342.

Gresse P.G., Chemale Jr. F., Silva L.C., Walraven F., Hartmann L.A. 1996. Late to post orogenic basins of the Pan-African-Brasiliano collision orogen in southern Africa and southern Brazil. Basin Research, 8:157-171.

Gründer A.L., Laporte D., Druitt T.H. 2005. Experimental and textural investigation of welding: effects of compaction, sintering, and vapor-phase crystallization in the rhyolitic Rattlesnake Tuff. J. Volcanol. Geotherm. Res., 142:89-104.

Guest J.E. \& Rogers P.S. 1967. The sintering of glass and its relationship to welding in ignimbrites. Proc. Geol. Soc. London, 1641:174-177.

Hanchar J.M. \& Watson E.B. 2003. Zircon saturation thermometry. In: Hanchar J. M. \& Hoskin P. W. O. (eds) Zircon. Rev. in Min. and Geoch., 53:89-112.

Henry C.D., Price J.G., Rubin J.N., Parker D.F., Wolff J.A., Self S., Franklin R., Barker D.S. 1988. Widespread, 
lava-like silicic volcanic rocks of Trans-Pecos Texas. Geology, 16:509-512.

Hergt J., Woodhead J., Schofield A. 2007. A-type magmatism in the Western Lachlan Fold Belt? A study of granites and rhyolites from the Grampians region, Western Victoria. Lithos, 97:122-139.

Janikian L., Almeida R.P., Trindade R.I.F., Fragoso-Cesar A.R.S., D’Agrella-Filho M.S., Dantas E.L., Tohver E. 2008. The continental record of Ediacaran volcanosedimentary successions in southern Brazil and their global implications. Terra Nova, 20:259-266.

Kano K., Matsuura H., Yamauchi S. 1997. Miocene rhyolitic welded tuff infilling a funnel-shaped eruption conduit Shiotani, southeast of Matsue, SW Japan. Bull. Volcanol. 59:125-135.

King P.L., White A.J.R., Chappell B.W., Allen C.M. 1997. Characterization and Origin of Aluminous A-type Granites from the Lachlan Fold Belt, Southeastern Australia. Journ. of Petr., 38(3):371-391.

Kobberger G. \& Schmincke H.U. 1999. Deposition of rheomorphic ignimbrite D (Mogan Formation) Gran Canaria, Canary Islands, Spain. Bull. Volcanol., 60:465485.

LeMaitreR.W.2002.Igneous rocks: aclassification and glossary of terms. In: Recommendations of the International Union of Geological Sciences Subcommission on the Systematic of Igneous Rocks. Cambridge, Cambridge University Press, $252 \mathrm{p}$.

Leat P.T., Jackson S.E., Thorpe R.S., Stillman C.J. 1986. Geochemistry of bimodal basalt - subalkaline/peralkaline rhyolite provinces within the Southern British Caledonides. Journal of Geological Society, 143:259-273.

Liégeois J.P. 1998. Preface - Some words on post-collisional magmatism. Lithos, 45:15-17.

Lima E.F., Sommer C.A., Nardi L.V.S. 2007. O vulcanismo neoproterozóico-ordoviciano no Escudo Sul-riograndense: os ciclos vulcânicos da Bacia do Camaquã. In: Iannuzzi R. \& Frantz J.C. (eds.) 50 Anos de Geologia. Instituto de Geociências. Contribuições. Porto Alegre, Comunicação e Identidade, p. 79-95.

Llambías E.J. 2003. Geología de los Cuerpos Ígneos. Buenos Aires, Asociación Geológica Argentina, $182 \mathrm{p}$.

MacDonald R. 1974. Nomenclature and Petrochemistry of the Peralkaline Oversaturated Extrusive Rocks. Bul. of Volcan, 38:498-516.

McBierney A.R. \& Murase T. 1984. Rheological Properties of Magmas. Ann. Rev. Earth Planet. Sci., 12:337-57

Naranjo J.A., Sparks R.S.J., Stasiuk M.V., Moreno H., Ablay G.J. 1992. Morphological, textural and structural variations in the 1988-1990 andesite lava of Lonquimay. Geol. Mag., 129:657-678.

Paim P.S.G., Chemale Jr. F., Lopes R.C. 2000. A Bacia do Camaquã. In: Holz M. \& De Ros L.F (eds.) Geologia do Rio Grande do Sul. Porto Alegre, CIGO/UFRGS, p. 231-374.

Patiño Douce A.E. 1997. Generation of metaluminous A-type granites by low-pressure melting of calc-alkaline granitoids. Geology, 25(8):743-746.

Peterson D.W. 1979. Significance of flattening of pumice fragments in ash-flow tuffs. In: Chapin, C.E., Elston,
W.E. (Eds.), Ash-Flow Tuffs and Associate Igneous Rocks. Spec. Pap. Geol. Soc. Am., 180:195-204.

Pierosan R., Lima E.F., Nardi L.V.S, Campos C.P., Bastos Neto A.C., Ferron J.M.T.M., Prado M. 2010. Paleoproterozoic $(\sim 1.88 \mathrm{Ga})$ felsic volcanism of the Iricoumé Group in the Pitinga Mining District area, Amazonian Craton, Brazil: insights in ancient volcanic processes from field and petrologic data. Anais da Acad. Bras. de Ciências (no prelo).

Quane S.L. \& Russell J.K. 2005. Welding: insights from high-temperature analogue experiments. J. Volcanol. Geotherm. Res., 142:67-87.

Quane S.L., Russell J.K., Kennedy L.A. 2004. A lowload high-temperature deformation apparatus for volcanological studies. Am. Mineral., 89:873-877.

Ragan D.H. \& Sheridan M.F. 1972. Compaction of the bishop Tuff, California. Geol. Soc. Am. Bull., 83:95-106.

Ribeiro M. \& Fantinel L.M 1978. Associações petrotectônicas do Escudo Sul-rio-grandense: I Tabulação e distribuição das associações petrotectônicas do Rio Grande do Sul. Iheringia, Série Geológica, 5:19-54.

Ribeiro M., Bocchi P.R., Figueiredo Filho P.M., Tessari R. 1966. Geologia da Quadrícula de Caçapava do Sul. Rio Grande do Sul. Bol. Div. Fom. Prod. Min. Bras., Rio de Janeiro, 127:1-232.

Riehle J.R., Miller T.F., Bailey R.A. 1995. Cooling, degassing and compaction of rhyolitic ash-flow tuffs: a computational model. Bull. Volcanol., 57:319-336.

Ross C.S. \& Smith R.L. 1961. Ash-flow tuffs, their origin, geologic relations and identification. USGS Journal Research Professional Paper, 366:81.

Schmincke H.U. 1974. Volcanological aspects of peralkaline silicic welded ash-flow tuffs. Bull Volcanol., 38:594-636

Schmincke H.U. \& Swanson D.A. 1967. Laminar viscous flowage structures in ash-flow tuffs from Gran Canaria, Canary Islands. J. Geol., 75:641-664.

Shaw H.R. 1972. Viscosities of magmatic silicate liquids: an empirical model of prediction. Am. J. Sci., 272:438- 475.

Sheridan M.F. 1979. Emplacement of pyroclastic flows: a review. Geological Society of America Special Paper, 180:125-136.

Sisson T.W. \& Grove T.L. 1993. Experimental investigations of the role of $\mathrm{H}_{2} \mathrm{O}$ in calc-alkaline differentiation and subduction zone magmatism. Contrib. Mineral. Petrol., 113:143-166:

Smith R.L. 1960a. Ash flows. Geological Society of America Bulletin, 71:795-842.

Smith R.L. 1960b. Zones and zonal variations in welded ashflows. USGS Journal Research Professional Paper, 354F:149-159.

Smith R.L. 1979. Ash-flow magmatism. In: Chapin, C.E., Elston, W.E. (Eds.), Ash-Flow Tuffs. Spec. Pap. Geol. Soc. Am., 180:5-27.

Sommer C.A. 1994. O vulcanismo ácido da porção sul do Platô do Taquarembó, Dom Pedrito-RS. Dissertação de mestrado, Instituto de Geociências, Universidade Federal do Rio Grande do Sul, Porto Alegre, 149 p.

Sommer C.A., Lima E.F., Nardi L.V.S. 1999. Evolução do vulcanismo alcalino na porção sul do Platô do Taquarembó, Dom Pedrito - RS. Revista Brasileira de Geociências, 29(2):245-254. 
Sommer C.A., Lima E.F., Nardi L.V.S., Liz J.D., Pierosan R. 2003. Depósitos de fluxo piroclástico primários: caracterização e estudo de um caso no vulcanismo ácido neoproterozóico do Escudo Sul-Rio-grandense. Pesquisas em Geociências, 30:3-26.

Sommer C.A., Lima E.F., Nardi L.V.S., Figueiredo A.M.G., Pierosan R. 2005. Potassic and Low- and High-Ti Mildly Alkaline Volcanism in the Neoproterozoic Ramada Plateau, Southernmost Brazil. Journal of South American Earth Sciences, 18:237-254.

Sommer C.A., Lima E.F., Nardi L.V.S, Liz J. D., Waichel B.L. 2006. The evolution of Neoproterozoic magmatism in southernmost Brazil: shoshonitic, high-K tholeiitic and silica-saturated, sodic alkaline volcanism in postcollisional basins. Anais da Academia Brasileira de Ciências, 78(3):573-589.

Sparks R.S.J., Self S., Walker G.P.L.1973. Products of ignimbrite eruptions. Geology, 1:115-118.

Sparks R.S.J. 1976. Grain size variations in ignimbrites and implications for the transport of pyroclastic flows. Sedimentology, 23:147-188.

Sparks R.S.J. \& Wright, J.V. 1979. Welded air-fall tuffs. In: Chapin C.E., Elston W.E. (eds.). Ash-Flow Tuffs. Spec. Pap. Geol. Soc. Am., 180:155-166.

Sparks R.S.J., Stasiuk M.V., Gardeweg M., Swanson D.A., 1993. Welded bressias in andesite lavas. J. Geol. Soc., 150:897-902.

Streck M.J. \& Grunder A.L. 1995. Crystallization and welding variations in a widespread ignimbrite sheet; the Rattlesnake Tuff, eastern Oregon, USA. Bull. Volcanol., 57:151-169.

Streck M.J. \& Grunder A.L. 1997. Compositional gradients and gaps in the high-silica rhyolites of the Rattlesnake Tuff, southeastern Oregon. J. Petrol., 38:133-163.

Tuffen H., Dingwell D.B., Pinkerton H. 2003. Repeated fracture and healing of silicic magma generate flow banding and earthquakes? Geology, 31:1089-1092.

Walker G.P.L. 1983. Ignimbrite types and ignimbrite problems. J. Volcanol. Geotherm. Res., 17:65-88

Watson E.B. 1979. Zircon saturation in felsic liquids: experimental data and application to trace element geochemistry. Contrib. to Min. and Petr., 70:407-419.
Watson E.B. \& Harrison T.M. 1983. Zircon saturation revisited: temperature and composition effects in a variety of crustal magma types. Earth and Plan. Sci. Lett., 64:295-304.

Wildner W., Lima E.F., Camozzato E., Lopes R.C. 1997. O Vulcanismo Neoproterozóico-Cambriano no Rio Grande do Sul: Estratigrafia e Aspectos Texturais. A Terra em Revista, 3(3):19-27.

Wildner W., Nardi L.V.S., Lima E.F. 1999. Post-collisional Alkaline Magmatism on the Taquarembó Plateau: a well Preserved Neoproterozoic-Cambrian Plutono-volcanic Association in Southern Brazil. International Geology Review, 41:1082-1098.

Wildner W., Lima E.F., Nardi L.V.S., Sommer C.A. 2002. Volcanic cycles and setting in the Neoproterozoic III to Ordovician Camaquã Basin succession in southern Brazil: characteristics of post-collisional magmatism. Journal of Volcanology and Geothermal Research, 118:261-283.

Wohletz K. 2007. Magma (Igneous rock norms, classification, and physical properties). Disponível em http://www.ees1. lanl.gov/Wohletz/Magma.htm. Acessado em: 10/11/2010.

Wolff J.A. \& Sumner J.M. 2000. Lava fountains and their products. In: Sigurdson H. (ed.). Encyclopedia of Volcanoes. San Diego, Academic Press, p. 321-329.

Wolff J.A. \& Wright J.V. 1981. Rheomorphism of welded tuffs. J. Volcanol. Geotherm. Res., 10:13-34.

Wrigth J.V., Smith A.L., Self S. 1980. A Working Terminology of Pyroclastic Deposits. Journal of Volcanology and Geothermal Research, 8:315-336.

Wright J.V., Walker G.P.L. 1981. Eruption, transport and deposition of ignimbrite: A case study from Mexico. $J$. Volcanol. Geotherm. Res., 9:111-131.

Zerfass H. \& Almeida D.M.P. 1997. Mapa Geológico da região dos Cerros do Bugio e Perau, Município de Caçapava do Sul, RS. Estudos Tecnológicos - Acta Geológica Leopoldensia (Série Mapas), 20:3-17.

Manuscrito ID 17667

Submetido em 13 de junho de 2010 Aceito em 13 de outubro de 2011 